\title{
INFLUÊNCIA DO MANEJO DO SOLO E DA ROTAÇÃO DE CULTURAS NA QUALIDADE INDUSTRIAL DO TRIGO'
}

\author{
ELIANA MARIA GUARIENTI², HENRIQUE PEREIRA DOS SANTOS ${ }^{3}$ e JÚLIO CÉSAR BARRENECHE LHAMBY ${ }^{4}$
}

\begin{abstract}
RESUMO - A qualidade industrial do trigo é afetada por fatores genéticos e ambientais, como solo, clima, tratos culturais, e outros. O presente trabalho teve como finalidade avaliar o efeito de sistemas de manejo de solo e de rotação de culturas sobre características que definem a qualidade industrial de trigo (peso do hectolitro, peso de mil grãos, extração experimental de farinha, alveografia, teste de microssedimentação com lauril sulfato de sódio e número de queda). O delineamento experimental foi em blocos ao acaso, com parcelas subdivididas e três repetições. A parcela principal foi constituída pelos sistemas de manejo de solo (plantio direto, preparos convencionais de solo com arado de discos e de aivecas, e cultivo mínimo), e a subparcela, pelos sistemas de rotação de culturas (monocultura, um inverno e dois invernos sem trigo). O preparo convencional de solo com arado de discos e o cultivo mínimo reduziu o número de queda; o sistema de rotação com dois invernos sem trigo elevou o peso do hectolitro; a monocultura desse cereal reduziu o peso do hectolitro, elevou a força geral de glúten e a microssedimentação com lauril sulfato de sódio; a interação sistemas de manejo de solo, rotação de culturas e ano de cultivo afetou o peso de mil grãos e, o ano de cultivo teve grande influência em todas as características de qualidade industrial de trigo estudadas.
\end{abstract}

Termos para indexação: Triticum aestivum, plantio direto, preparo convencional de solo, cultivo mínimo, fatores edáficos, relação planta-solo.

\section{INFLUENCE OF SOIL MANAGEMENT AND CROP ROTATION ON CHARACTERISTICS THAT DEFINE THE INDUSTRIAL QUALITY OF WHEAT}

\begin{abstract}
Wheat quality is affected by genetic and environmental factors such as soil, climate and cultural traits. The objective of this study was to evaluate the effect of soil management and crop rotation systems on characteristics that define wheat industrial quality (hectoliter weight, thousandkernel weight, milling quality, alveograph characteristics, sodium dodecyl sulphate microsedimentation test and falling number). The experimental design used was in complete randomized blocks, with split plots and three replications. Main plot consisted of the soil management systems (no-tillage system, conventional tillage with disc and moldboard plough and minimum tillage) and the subplot consisted of the crop rotation systems (monoculture, one winter and two winters without wheat). Conventional soil preparations with discs' plough reduced the falling number; the crop rotation systems with two winters without wheat increased the hectoliter weight; the monoculture of this cereal reduced the hectoliter weight, increased the gluten strength and the values obtained in the microsedimentation test with sodium lauril sulphate; the interaction of soil management, crop rotation system and year of management affected the weight of one-thousand grains and the year of cultivation had great influence in all characteristics of the industrial quality of wheat.
\end{abstract}

Index terms: Triticum aestivum, direct sowing, conventional tillage, minimum tillage, edaphic factors, plant soil relations.

\footnotetext{
${ }^{1}$ Aceito para publicação em 10 de fevereiro de 2000.

${ }^{2}$ Eng. Agrôn., M.Sc., Embrapa-Centro Nacional de Pesquisa de Trigo (CNPT), Caixa Postal 451, CEP 99001-970 Passo Fundo, RS. E-mail: eliana@cnpt.embrapa.br

${ }^{3}$ Eng. Agrôn., Dr., Embrapa-CNPT. Bolsista do CNPq.

E-mail: hpsantos@cnpt.embrapa.br

${ }^{4}$ Eng. Agrôn., Dr., Embrapa-CNPT.

E-mail: julio@cnpt.embrapa.br
}

\section{INTRODUÇÃO}

Sistemas de manejo de solo compatíveis com as características edafoclimáticas de cada região, associados à rotação de culturas, são imprescindíveis para a manutenção de um sistema produtivo, pois interrompem o processo de degradação do solo, manten- 
do a lavoura economicamente viável e integrada no processo de produção agrícola (Instituto Agronômico do Paraná, 1997).

As condições de ambiente (solo, práticas culturais, clima, e outras) influenciam o genótipo, e várias outras características dos grãos e da farinha, e determinam a aptidão dos trigos para os diferentes usos industriais (Bequette, 1989).

Para avaliar a qualidade dos grãos e da farinha de trigo, Mandarino (1993) sugere que sejam realizadas análises físicas (peso do hectolitro e peso de mil grãos), físico-químicas (teste de microssedimentação com sulfato dodecil de sódio e número de queda), além da análise tecnológica de alveografia.

O teste de número de queda tem por finalidade verificar a atividade da enzima alfa-amilase do grão, a fim de detectar danos causados pela germinação na espiga (Perten, 1964). A redução no número de queda pode representar um grande prejuízo ao agricultor, já que este é um dos critérios de classificação comercial adotado em nosso país (Brasil, 1999).

Autores de vários países estudaram o efeito da adubação nitrogenada (Hucklesby et al., 1971; Campbell et al., 1977; Borghi et al., 1995; Jia et al., 1996), de fungicidas (Jia et al., 1996), e de condições de colheita (Rao et al., 1993) na qualidade industrial de trigo. No entanto, a influência do manejo de solo e da rotação de culturas na qualidade de trigo foi relativamente pouco estudada.

Borghi et al. (1995) verificaram que a rotação de culturas promove significativo efeito na qualidade do trigo. Esses autores concluíram que o sistema de rotação milho/trigo/alfafa incrementou a quantidade de proteínas e os valores alveográficos, comparativamente à rotação de milho/trigo. No entanto, a maior concentração de proteínas foi obtida com a monocultura de trigo.

Segundo López-Bellido et al. (1998), os sistemas de rotação de culturas que envolvem uma leguminosa, como o grão-de-bico e a fava, apresentam marcante efeito na qualidade do trigo, pois além de incrementar a produção, e o conteúdo de proteína, melhoram as propriedades reológicas.

O presente estudo teve como finalidade avaliar o efeito de sistemas de manejo de solo e de rotação de culturas sobre características que definem a qualidade industrial do trigo.

\section{MATERIAL E MÉTODOS}

Um dos projetos desenvolvidos na Embrapa-Centro Nacional de Pesquisa de Trigo (Embrapa-CNPT), em Passo Fundo, RS, durante o período de 1986 a 1995, teve como objetivo a avaliação dos efeitos de sistemas de manejo de solo e de rotação de culturas de inverno sobre o rendimento dos grãos de trigo. Na Tabela 1 são apresentadas informações sobre os sistemas de manejo do solo e de rotação de culturas para trigo usados nesses anos de estudo. Nos anos de 1994 e 1995 coletaram-se amostras para as avaliações que deram origem ao presente trabalho.

O solo do Município de Passo Fundo foi classificado como Latossolo Vermelho-Escuro distrófico. A altitude do local de plantio é de $684 \mathrm{~m}$. Na Tabela 2, são apresentadas informações sobre precipitação pluvial, temperatura e umidade relativa do ar, do período de junho a outubro, nos anos de execução do experimento, e na Tabela 3, pode-se verificar o rendimento de grãos obtidos neste ensaio.

$\mathrm{O}$ delineamento experimental usado foi em blocos ao acaso, com parcelas subdivididas e três repetições. A parcela principal foi constituída pelos sistemas de manejo de solo (plantio direto, preparo convencional de solo com arado de discos, preparo convencional de solo com arado de aivecas, e preparo de solo com implemento de cultivo mínimo JAN), e a subparcela, pelos sistemas de rotação de culturas para trigo (monocultura trigo/soja; um inverno sem trigo: trigo/soja e ervilhaca/milho, e dois invernos sem trigo: trigo/soja, aveia-branca e ervilhaca/milho). A parcela principal mediu $360 \mathrm{~m}^{2}$ (4 m de largura por $90 \mathrm{~m}$ de comprimento), e a subparcela, $40 \mathrm{~m}^{2}$ ( $4 \mathrm{~m}$ de largura por $10 \mathrm{~m}$ de comprimento), e a área útil colhida foi de $17 \mathrm{~m}^{2}$ (1,7 m de largura por $10 \mathrm{~m}$ de comprimento).

A semeadura, o controle de plantas daninhas e os tratamentos fitossanitários foram realizados conforme as recomendações para cada cultura, quando necessário. A colheita foi realizada com automotriz especial para parcelas, marca Nursery - Master Hidrostatic, com picador de palha adaptado.

Os grãos colhidos nas diferentes subparcelas foram analisados no Laboratório de Qualidade Industrial de Trigo, da Embrapa-CNPT, e avaliados pelos seguintes testes: peso do hectolitro, com balança de peso do hectolitro Dalle Molle, seguindo o método indicado pelo fabricante (Balanças Dalle Molle, 19--); peso de mil grãos, pelo método descrito em Brasil (1992); extração experimental de farinha pelo moinho experimental Quadrumat Senior, da marca Brabender, segundo o método AACC no 26/94 (American Association of Cereal Chemists, 1983); alveografia, pelo método de análise da AACC no 54/30 (American Association of Cereal Chemists, 1983). Consi- 
TABELA 1. Sistemas de manejo de solo e de rotação de culturas para trigo. Passo Fundo, RS ${ }^{1}$.

\begin{tabular}{|c|c|c|c|c|c|c|c|c|c|c|c|c|c|c|}
\hline \multirow{2}{*}{$\begin{array}{l}\text { Sistema } \\
\text { de rotação }\end{array}$} & \multicolumn{4}{|c|}{ Parcela principal } & \multicolumn{10}{|c|}{ Subparcela } \\
\hline & & & & & 1986 & 1987 & 1988 & 1989 & 1990 & 1991 & 1992 & 1993 & 1994 & 1995 \\
\hline Monocultura & PD & PCD & PCA & $\mathrm{CM}$ & $\mathrm{T} / \mathrm{S}$ & $\mathrm{T} / \mathrm{S}$ & $\mathrm{T} / \mathrm{S}$ & $\mathrm{T} / \mathrm{S}$ & $\mathrm{T} / \mathrm{S}$ & $\mathrm{T} / \mathrm{S}$ & $\mathrm{T} / \mathrm{S}$ & $\mathrm{T} / \mathrm{S}$ & $\mathrm{T} / \mathrm{S}$ & $\mathrm{T} / \mathrm{S}$ \\
\hline \multirow{2}{*}{$\begin{array}{l}\text { Um inverno } \\
\text { sem trigo }\end{array}$} & PD & PCD & PCA & $\mathrm{CM}$ & $\mathrm{T} / \mathrm{S}$ & $\mathrm{E} / \mathrm{M}$ & $\mathrm{T} / \mathrm{S}$ & $\mathrm{E} / \mathrm{M}$ & $\mathrm{T} / \mathrm{S}$ & $\mathrm{E} / \mathrm{M}$ & $\mathrm{T} / \mathrm{S}$ & $\mathrm{E} / \mathrm{M}$ & $\mathrm{T} / \mathrm{S}$ & E/So \\
\hline & PD & PCD & PCA & $\mathrm{CM}$ & $\mathrm{E} / \mathrm{M}$ & $\mathrm{T} / \mathrm{S}$ & $\mathrm{E} / \mathrm{M}$ & $\mathrm{T} / \mathrm{S}$ & $\mathrm{E} / \mathrm{M}$ & $\mathrm{T} / \mathrm{S}$ & $\mathrm{E} / \mathrm{M}$ & $\mathrm{T} / \mathrm{S}$ & E/So & $\mathrm{T} / \mathrm{S}$ \\
\hline \multirow{3}{*}{$\begin{array}{l}\text { Dois } \\
\text { invernos } \\
\text { sem trigo }\end{array}$} & PD & PCD & PCA & $\mathrm{CM}$ & $\mathrm{T} / \mathrm{S}$ & $\mathrm{Ap} / \mathrm{S}$ & $\mathrm{E} / \mathrm{M}$ & $\mathrm{T} / \mathrm{S}$ & $\mathrm{E} / \mathrm{M}$ & $\mathrm{Ab} / \mathrm{S}$ & $\mathrm{T} / \mathrm{S}$ & $\mathrm{E} / \mathrm{M}$ & $\mathrm{Ab} / \mathrm{S}$ & $\mathrm{T} / \mathrm{S}$ \\
\hline & PD & PCD & PCA & $\mathrm{CM}$ & $\mathrm{Ap} / \mathrm{S}$ & $\mathrm{E} / \mathrm{M}$ & $\mathrm{T} / \mathrm{S}$ & $\mathrm{Ap} / \mathrm{S}$ & $\mathrm{Ab} / \mathrm{S}$ & $\mathrm{T} / \mathrm{S}$ & $\mathrm{E} / \mathrm{M}$ & $\mathrm{Ab} / \mathrm{S}$ & $\mathrm{T} / \mathrm{S}$ & E/So \\
\hline & PD & PCD & PCA & $\mathrm{CM}$ & $\mathrm{E} / \mathrm{M}$ & $\mathrm{T} / \mathrm{S}$ & $\mathrm{Ap} / \mathrm{S}$ & $\mathrm{E} / \mathrm{M}$ & $\mathrm{T} / \mathrm{S}$ & $\mathrm{E} / \mathrm{M}$ & $\mathrm{Ab} / \mathrm{S}$ & $\mathrm{T} / \mathrm{S}$ & E/So & $\mathrm{Ab} / \mathrm{S}$ \\
\hline
\end{tabular}
mínimo; Ab: aveia-branca; Ap: aveia-preta; E: ervilhaca; M: milho; S: soja; So: sorgo; T: trigo.

TABELA 2. Informações sobre precipitação pluvial, temperatura e umidade relativa do ar, do período de junho a outubro de 1994 e de 1995, ocorridas em Passo Fundo, RS.

\begin{tabular}{|c|c|c|c|c|c|}
\hline \multirow[t]{2}{*}{ Ano } & \multicolumn{5}{|c|}{ Mês } \\
\hline & Jun. & Jul. & Ago & Set. & Out. \\
\hline & \multicolumn{5}{|c|}{ Precipitação pluvial (mm) } \\
\hline 1994 & 199 & 243 & 46 & 162 & 309 \\
\hline 1995 & 175 & 136 & 76 & 135 & 199 \\
\hline & \multicolumn{5}{|c|}{ Temperatura $\left({ }^{\circ} \mathrm{C}\right)$ em 1994} \\
\hline Mínima & 8,8 & 9,8 & 9,8 & 11,9 & 14,9 \\
\hline Média & 12,4 & 13,5 & 14,5 & 16,6 & 18,8 \\
\hline Máxima & 17,9 & 18,8 & 21,4 & 23,1 & 24,2 \\
\hline & \multicolumn{5}{|c|}{ Temperatura $\left({ }^{\circ} \mathrm{C}\right)$ em 1995} \\
\hline Mínima & 9,7 & 11,5 & 10,8 & 11,0 & 11,7 \\
\hline Média & 13,7 & 15,2 & 15,4 & 15,4 & 16,7 \\
\hline Máxima & 20,0 & 20,9 & 22,0 & 21,6 & 22,8 \\
\hline \multicolumn{6}{|c|}{ Umidade relativa (\%) } \\
\hline 1994 & 78 & 75 & 69 & 71 & 77 \\
\hline 1995 & 77 & 77 & 70 & 71 & 65 \\
\hline
\end{tabular}

TABELA 3. Rendimento de grãos do trigo EMBRAPA 16 obtido em três sistemas de rotação de culturas, em 1994 e 1995. Passo Fundo, RS.

\begin{tabular}{lccc}
\hline \multirow{2}{*}{$\begin{array}{l}\text { Sistema de rotação de } \\
\text { culturas }\end{array}$} & \multicolumn{2}{c}{ Ano de cultivo } & \multirow{2}{*}{ Média } \\
\cline { 2 - 3 } & 1994 & 1995 & \\
\hline Monocultura $^{1}$ & 2.490 & 2.238 & $2.364,0$ \\
Um inverno sem trigo $^{2}$ & 3.434 & 3.063 & $3.248,5$ \\
Dois invernos sem trigo $^{3}$ & 3.496 & 2.504 & $3.000,0$ \\
\hline${ }^{1}$ Monocultura trigo/soja. & & \\
${ }^{2}$ Trigo/soja e ervilhaca/milho. \\
${ }^{3}$ Trigo/soja, aveia-branca e ervilhaca/milho. & \\
& & \\
Fonte: Santos et al. (1998). & & &
\end{tabular}

deraram-se apenas valores de força geral de glúten (W) e da relação entre a tenacidade e a extensibilidade $(\mathrm{P} / \mathrm{L})$; teste de microssedimentação com lauril sulfato de sódio, pelo método proposto por Axford et al. (1978); e número de queda, pelo método proposto por Perten (1964).

Para a análise da variância, os dados foram avaliados usando-se o "procedimento de modelos" linear geral SAS (SAS Institute, 1987).

Foi realizada análise da variância de cada característica qualitativa, dentro de cada ano, dos sistemas de manejo de solo e dos sistemas de rotação de culturas, além da análise das diferentes interações, seguindo recomendações de Pimentel-Gomes (1973). Considerou-se o efeito do ano como aleatório, e o efeito dos diferentes tratamentos, como fixo. A comparação de médias foi feita pela aplicação do teste de Duncan, a 5\% de probabilidade.

\section{RESULTADOS E DISCUSSÃO}

O resumo da análise da variância (quadrados médios) é apresentado na Tabela 4. O ano de cultivo apresentou grande influência em todas as características de qualidade industrial estudadas (Tabela 5). Em 1994, comparativamente aos valores obtidos em 1995, houve redução das características físicas do grão (peso do hectolitro e peso de mil grãos), bem como na força geral de glúten, na microssedimentação com lauril sulfato de sódio e no número de queda. A precipitação pluvial, em 1994, foi superior à observada em 1995 (Tabela 2), sendo os valores acumulados de junho a outubro, da ordem de 959 e de $721 \mathrm{~mm}$, respectivamente. Nos meses de setembro-outubro, correspondendo às fases de enchimento de grãos e 
TABELA 4. Quadrados médios do peso do hectolitro (PH), do peso de mil grãos (PMG), da extração experimental de farinha (EXT), da força geral de glúten (W), da relação tenacidade/extensibilidade (P/L), do número de queda (NQ) e da microssedimentação com lauril sulfato de sódio (MS-SDS) do trigo EMBRAPA 16, submetido a dois anos de cultivo, quatro sistemas de manejo de solo e três sistemas de rotação de culturas. Passo Fundo, RS, 2000.

\begin{tabular}{lrrrrrrr}
\hline Fonte de variação & \multicolumn{1}{c}{ PH } & PMG & \multicolumn{1}{c}{ EXT } & W & P/L & NQ & MS-SDS \\
\hline Ano & $631,90^{*}$ & $82,77^{*}$ & $855,10^{*}$ & $5460,12^{*}$ & $1,30^{*}$ & $768180,13^{*}$ & $31,47^{*}$ \\
Manejo & $5,40^{*}$ & $6,10^{*}$ & $6,05^{\text {ns }}$ & $865,16^{\text {ns }}$ & $0,01^{\text {ns }}$ & $3811,05^{*}$ & $1,77^{*}$ \\
Sistema & $17,82^{*}$ & $66,67^{*}$ & $39,51^{*}$ & $14854,68^{*}$ & $0,04^{\text {ns }}$ & $5565,01^{*}$ & $14,26^{*}$ \\
Ano x manejo & $1,81^{\text {ns }}$ & $1,10^{\text {ns }}$ & $2,93^{\text {ns }}$ & $2019,38^{\text {ns }}$ & $0,06^{\text {ns }}$ & $1983,79^{*}$ & $0,67^{\text {ns }}$ \\
Ano x sistema & $13,00^{*}$ & $1,52^{\text {ns }}$ & $6,90^{\text {ns }}$ & $6318,79^{*}$ & $0,20^{*}$ & $2243,79^{\text {ns }}$ & $4,87^{*}$ \\
Manejo x sistema & $2,63^{\text {ns }}$ & $1,90^{\text {ns }}$ & $5,64^{\text {ns }}$ & $343,11^{\text {ns }}$ & $0,02^{\text {ns }}$ & $627,66^{\text {ns }}$ & $0,13^{\text {ns }}$ \\
Ano x manejo x sistema & $1,02^{\text {ns }}$ & $4,25^{*}$ & $2,03^{\text {ns }}$ & $747,66^{\text {ns }}$ & $0,04^{\text {ns }}$ & $1307,51^{\text {ns }}$ & $0,40^{\text {ns }}$ \\
\hline
\end{tabular}

${ }_{\text {ns }}$ e * Não-significativo e significativo a $5 \%$ de probabilidade, respectivamente, pelo teste $\mathrm{F}$.

TABELA 5. Efeito de anos de cultivo e de sistemas de manejo de solo (plantio direto - PD; preparo convencional de solo com arado de discos - PCD; preparo convencional de solo com arado de aivecas - PCA; cultivo mínimo - CM) na qualidade industrial do trigo EMBRAPA 16. Passo Fundo, RS, 20001.

\begin{tabular}{|c|c|c|c|c|c|c|}
\hline \multirow[t]{2}{*}{ Ano de cultivo } & \multicolumn{4}{|c|}{ Sistemas de manejo de solo } & \multirow[t]{2}{*}{ Média } & \multirow{2}{*}{$\begin{array}{c}\text { Coef. de } \\
\text { variação (\% }\end{array}$} \\
\hline & $\mathrm{PD}$ & PCD & PCA & $\mathrm{CM}$ & & \\
\hline \multicolumn{7}{|c|}{ Peso do hectolitro $(\mathrm{kg} / \mathrm{hL})$} \\
\hline 1994 & $70,54 \mathrm{aA}$ & $70,27 \mathrm{aA}$ & $71,06 \mathrm{aA}$ & $69,29 \mathrm{aA}$ & $70,29 \mathrm{~b}$ & 1,92 \\
\hline 1995 & $76,74 \mathrm{aA}$ & $76,48 \mathrm{aA}$ & $76,03 \mathrm{aA}$ & $75,61 \mathrm{aA}$ & $76,21 \mathrm{a}$ & 1,28 \\
\hline Média & $73,64 \mathrm{~A}$ & $73,37 \mathrm{~A}$ & $73,54 \mathrm{~A}$ & $72,45 \mathrm{~A}$ & & \\
\hline \multicolumn{7}{|c|}{ Peso de mil grãos (g) } \\
\hline 1994 & $32,87 \mathrm{aA}$ & $31,66 \mathrm{aA}$ & $32,47 \mathrm{aA}$ & $33,57 \mathrm{aA}$ & $32,64 \mathrm{~b}$ & 2,33 \\
\hline 1995 & $35,18 \mathrm{aA}$ & $34,33 \mathrm{aA}$ & $34,56 \mathrm{aA}$ & $35,07 \mathrm{aA}$ & $34,78 \mathrm{a}$ & 1,64 \\
\hline Média & $34,02 \mathrm{~A}$ & $32,99 \mathrm{~A}$ & $33,51 \mathrm{~A}$ & $34,31 \mathrm{~A}$ & & \\
\hline \multicolumn{7}{|c|}{ Extração experimental de farinha (\%, base $14 \%$ de umidade) } \\
\hline 1994 & $65,16 \mathrm{aA}$ & $65,27 \mathrm{aA}$ & $65,59 \mathrm{aA}$ & $65,61 \mathrm{aA}$ & $65,41 \mathrm{a}$ & 2,85 \\
\hline 1995 & $57,93 \mathrm{aA}$ & $57,68 \mathrm{aA}$ & $59,86 \mathrm{aA}$ & $58,59 \mathrm{aA}$ & $58,51 \mathrm{~b}$ & 3,29 \\
\hline Média & $61,54 \mathrm{~A}$ & $61,48 \mathrm{~A}$ & $62,72 \mathrm{~A}$ & $62,10 \mathrm{~A}$ & & \\
\hline \multicolumn{7}{|c|}{ Força geral de glúten $\left(10^{-4} \mathrm{~J}\right)$} \\
\hline 1994 & $185,67 \mathrm{aA}$ & $216,00 \mathrm{aA}$ & $208,11 \mathrm{aA}$ & $189,33 \mathrm{aA}$ & $199,78 b$ & 16,83 \\
\hline 1995 & $214,33 \mathrm{aA}$ & $203,78 \mathrm{aA}$ & $225,44 \mathrm{aA}$ & $225,22 \mathrm{aA}$ & $217,19 \mathrm{a}$ & 5,82 \\
\hline Média & $200,00 \mathrm{~A}$ & $209,89 \mathrm{~A}$ & $216,78 \mathrm{~A}$ & $207,28 \mathrm{~A}$ & & \\
\hline \multicolumn{7}{|c|}{$\mathrm{P} / \mathrm{L}^{2}$} \\
\hline 1994 & $0,93 \mathrm{aA}$ & $1,04 \mathrm{aA}$ & $1,08 \mathrm{aA}$ & $0,90 \mathrm{aA}$ & $0,99 \mathrm{a}$ & 27,14 \\
\hline 1995 & $0,70 \mathrm{aA}$ & $0,70 \mathrm{aA}$ & $0,69 \mathrm{aA}$ & $0,78 \mathrm{aA}$ & $0,72 b$ & 11,18 \\
\hline Média & $0,81 \mathrm{~A}$ & $0,87 \mathrm{~A}$ & $0,88 \mathrm{~A}$ & $0,84 \mathrm{~A}$ & & \\
\hline \multicolumn{7}{|c|}{ Microssedimentação com lauril sulfato de sódio (mL) } \\
\hline 1994 & $12,87 \mathrm{aA}$ & $13,78 \mathrm{aA}$ & $13,44 \mathrm{aA}$ & $13,18 \mathrm{aA}$ & $13,32 b$ & 4,01 \\
\hline 1995 & $14,44 \mathrm{aA}$ & $14,62 \mathrm{aA}$ & $15,13 \mathrm{aA}$ & $14,36 \mathrm{aA}$ & $14,64 \mathrm{a}$ & 3,41 \\
\hline Média & $13,66 \mathrm{~A}$ & $14,20 \mathrm{~A}$ & $14,29 \mathrm{~A}$ & $13,77 \mathrm{~A}$ & & \\
\hline \multicolumn{7}{|c|}{ Número de queda (segundos) } \\
\hline 1994 & $193,78 \mathrm{bA}$ & $187,22 \mathrm{bA}$ & $224,33 \mathrm{bA}$ & $168,89 \mathrm{bB}$ & $193,55 b$ & 11,98 \\
\hline 1995 & $411,22 \mathrm{aA}$ & $386,67 \mathrm{aB}$ & $405,11 \mathrm{aA}$ & $397,55 \mathrm{aB}$ & $400,14 \mathrm{a}$ & 4,01 \\
\hline Média & $302,5 \mathrm{~A}$ & $286,94 B$ & $314,72 \mathrm{~A}$ & $283,22 \mathrm{~B}$ & & \\
\hline
\end{tabular}


de início da maturação do trigo, a precipitação acumulada em 1994 foi de $471 \mathrm{~mm}$, e em 1995, de $334 \mathrm{~mm}$.

Segundo Noda et al. (1994), a germinação pré-colheita do trigo é induzida quando os grãos absorvem água a baixas temperaturas, e com isso, a enzima $\alpha$-amilase sintetizada na camada de aleurona do endosperma e no escutelo do embrião é responsável pela redução da qualidade da farinha. Finney \& Yamazaki (1967) sugerem que o molhamento causado pela chuva e posterior secagem dos grãos reduzem o peso do hectolitro, em conseqüência da diminuição de sua densidade. De acordo com Bhatt et al. (1981), a redução do peso do hectolitro é resultante da alta taxa de respiração, associada aos grãos germinados, que consomem carboidratos acumulados nos grãos. Hirano (1976) observou que a precipitação pluvial antes da maturação fisiológica do trigo promove decréscimo no enchimento do grão, diminuindo o peso de mil grãos e aumentando a atividade enzimática. Esta última é a principal causa da redução das características qualitativas da farinha, pois as enzimas ativadas promovem alterações no amido e nas proteínas. De acordo com este mesmo autor, o estádio de maturação em que se encontram os grãos no momento em que recebe molhamento pode determinar redução ou acréscimo na extração de farinha.

Na média dos anos estudados, o peso do hectolitro, o peso de mil grãos, a extração experimental de farinha, a força geral de glúten, a relação P/L e a microssedimentação com lauril sulfato de sódio não apresentaram diferenças significativas em relação aos sistemas de manejo de solo (Tabela 5). Nesse mesmo período, o cultivo mínimo e o preparo convencional do solo com arado de discos propiciaram redução no número de queda, em relação aos demais sistemas de manejo do solo.

Na média dos anos estudados também não houve diferenças significativas entre os sistemas de rotação de culturas, no peso de mil grãos, na extração experimental de farinha, na relação $\mathrm{P} / \mathrm{L}$ e no número de queda (Tabela 6). O sistema de rotação de culturas com dois invernos sem trigo apresentou o maior valor de peso do hectolitro, enquanto no sistema um inverno sem trigo (trigo/soja e ervilhaca/milho) e na monocultura trigo/soja, os valores médios não diferiram. Santos et al. (1996) obtiveram menor peso do hectolitro na monocultura, em ensaios de rotação de culturas sobre o trigo, realizados em Guarapuava, PR. A monocultura apresentou maior valor de força geral de glúten e de microssedimentação com lauril sulfato de sódio. Este fato parece estar relacionado com a mais baixa produção de grãos obtida neste sistema, comparativamente aos demais (Tabela 3). De acordo com Zentner et al. (1990) e Borghi et al. (1995), o incremento na produção de grãos pode resultar na diluição do $\mathrm{N}$ na planta, fator este que pode comprometer a qualidade de glúten.

O sistema de rotação dois invernos sem trigo, que envolveu a presença da ervilhaca, não repercutiu no incremento da força geral de glúten. Este fato seria esperado em um sistema de rotação de culturas que envolvesse uma leguminosa, o que demonstra que a melhoria da força geral de glúten obtida por LópezBellido et al. (1998) quando utilizaram o grão-de-bico e a fava, em sistemas de rotação de culturas, não foi comprovada em relação à ervilhaca.

Observou-se que a relação $\mathrm{P} / \mathrm{L}$ foi menor no sistema de rotação um inverno sem trigo (trigo/soja e ervilhaca/milho) e no ano de 1994. Nos demais tratamentos e na média dos resultados, foram observadas diferenças significativas.

A interação sistemas de manejo de solo, de rotação de culturas e ano de cultivo foi significativa apenas para o peso de mil grãos (Tabela 7). Na média dos resultados de anos x métodos de manejo do solo, os maiores valores do peso de mil grãos foram obtidos em 1995, independentemente do sistema de manejo empregado. Entretanto, o preparo convencional do solo com arado de discos foi estatisticamente semelhante ao cultivo mínimo em 1994.

Na média dos sistemas de rotação de culturas, a monocultura foi responsável pela redução do peso de mil grãos, enquanto um e dois invernos sem trigo não apresentaram diferenças significativas. Santos et al. (1996) verificaram que a monocultura pode reduzir o peso de mil grãos. Com relação ao ano de cultivo, em 1994, no preparo convencional de solo com arado de disco, observou-se redução significativa no peso de mil grãos, quando foi utilizada a monocultura. Em 1995, a monocultura não afetou o peso de mil grãos, independentemente do método de manejo do solo. 
TABELA 6. Efeito de anos de cultivo e de sistemas de rotação de culturas na qualidade industrial do trigo EMBRAPA 16. Passo Fundo, RS, 2000'.

\begin{tabular}{|c|c|c|c|c|c|}
\hline \multirow[t]{2}{*}{ Ano de cultivo } & \multicolumn{3}{|c|}{ Sistemas de rotação de culturas } & \multirow[t]{2}{*}{ Média } & \multirow{2}{*}{$\begin{array}{c}\text { Coef. de } \\
\text { variação (\%) }\end{array}$} \\
\hline & Monocultura $^{2}$ & $\begin{array}{c}\text { Um inverno sem } \\
\text { trigo }^{3}\end{array}$ & $\begin{array}{c}\text { Dois invernos sem } \\
\text { trigo }^{4}\end{array}$ & & \\
\hline & \multicolumn{5}{|c|}{ Peso do hectolitro $(\mathrm{kg} / \mathrm{hL})$} \\
\hline 1994 & $69,71 \mathrm{bA}$ & $70,52 \mathrm{bA}$ & $70,64 \mathrm{bA}$ & $70,29 b$ & 2,12 \\
\hline 1995 & $75,99 \mathrm{aB}$ & $74,81 \mathrm{aC}$ & $77,84 \mathrm{aA}$ & $76,21 \mathrm{a}$ & 1,23 \\
\hline \multirow[t]{2}{*}{ Média } & $72,86 \mathrm{~B}$ & $72,66 \mathrm{~B}$ & $74,24 \mathrm{~A}$ & & \\
\hline & \multicolumn{5}{|c|}{ Peso de mil grãos $(\mathrm{g})$} \\
\hline 1994 & $30,84 \mathrm{aA}$ & $33,26 \mathrm{aA}$ & $33,82 \mathrm{aA}$ & $32,64 \mathrm{~b}$ & 4,76 \\
\hline 1995 & $32,73 \mathrm{aA}$ & $35,98 \mathrm{aA}$ & $35,63 \mathrm{aA}$ & $34,78 \mathrm{a}$ & 2,40 \\
\hline \multirow[t]{2}{*}{ Média } & $31,79 \mathrm{~A}$ & $34,62 \mathrm{~A}$ & $34,72 \mathrm{~A}$ & & \\
\hline & \multicolumn{5}{|c|}{ Extração experimental de farinha (\%, base $14 \%$ de umidade) } \\
\hline 1994 & $64,27 \mathrm{aA}$ & $66,58 \mathrm{aA}$ & $65,37 \mathrm{aA}$ & $65,40 \mathrm{a}$ & 2,92 \\
\hline 1995 & $56,70 \mathrm{bA}$ & $59,12 \mathrm{bA}$ & $59,71 \mathrm{bA}$ & $58,51 \mathrm{~b}$ & 3,53 \\
\hline \multirow[t]{2}{*}{ Média } & $60,49 \mathrm{~A}$ & $62,85 \mathrm{~A}$ & $62,54 \mathrm{~A}$ & & \\
\hline & \multicolumn{5}{|c|}{ Força geral de glúten $\left(10^{-4} \mathrm{~J}\right)$} \\
\hline 1994 & $245,00 \mathrm{aA}$ & $189,17 \mathrm{aB}$ & $165,17 \mathrm{bC}$ & $199,78 b$ & 17,35 \\
\hline 1995 & $227,92 \mathrm{aA}$ & $211,17 \mathrm{aA}$ & $212,50 \mathrm{aA}$ & $217,19 \mathrm{a}$ & 8,63 \\
\hline \multirow[t]{2}{*}{ Média } & $236,46 \mathrm{~A}$ & $200,17 \mathrm{~B}$ & $188,83 \mathrm{~B}$ & & \\
\hline & \multicolumn{5}{|c|}{$\mathrm{P} / \mathrm{L}^{5}$} \\
\hline 1994 & $1,116 \mathrm{aA}$ & $0,876 \mathrm{aB}$ & $0,971 \mathrm{aA}$ & $0,988 \mathrm{a}$ & 24,58 \\
\hline 1995 & $0,678 \mathrm{bA}$ & $0,804 \mathrm{aA}$ & $0,673 \mathrm{bA}$ & $0,719 \mathrm{~b}$ & 12,94 \\
\hline Média & $0,897 \mathrm{~A}$ & $0,840 \mathrm{~A}$ & $0,822 \mathrm{~A}$ & & \\
\hline \multicolumn{6}{|c|}{ Microssedimentação com lauril sulfato de sódio $(\mathrm{mL})$} \\
\hline 1994 & $14,38 \mathrm{bA}$ & $13,32 \mathrm{bB}$ & $12,25 \mathrm{bC}$ & $13,32 b$ & 4,89 \\
\hline 1995 & $15,33 \mathrm{aA}$ & $13,98 \mathrm{aB}$ & $14,60 \mathrm{aB}$ & $14,64 \mathrm{a}$ & 6,10 \\
\hline Média & $14,86 \mathrm{~A}$ & $13,65 \mathrm{~B}$ & $13,42 \mathrm{~B}$ & & \\
\hline & \multicolumn{5}{|c|}{ Número de queda (segundos) } \\
\hline 1994 & $217,83 \mathrm{bA}$ & $193,67 \mathrm{bA}$ & $169,17 \mathrm{bA}$ & $193,56 b$ & 14,29 \\
\hline 1995 & $402,83 \mathrm{aA}$ & $406,08 \mathrm{aA}$ & $391,50 \mathrm{aA}$ & $400,14 a$ & 8,43 \\
\hline Média & $310,33 \mathrm{~A}$ & $299,88 \mathrm{~A}$ & $280,33 \mathrm{~A}$ & & \\
\hline $\begin{array}{l}{ }^{1} \text { Médias seguidas } \\
\text { teste de Duncan. } \\
{ }^{2} \text { Monocultura trig } \\
3 \text { Trigo/soja e ervil } \\
{ }^{4} \text { Trigo/soja, aveia- } \\
{ }^{5} \text { P: tenacidade; L: }\end{array}$ & letra, minúscula n & e maiúscula na linha, & apresentam diferenças s & icativas a $5 \%$ & obabilidade, pelo \\
\hline
\end{tabular}

TABELA 7. Efeito de ano de cultivo, e de sistemas de manejo de solo (plantio direto - PD; preparo convencional de solo com arado de discos - PCD; preparo convencional de solo com arado de aivecas - PCA; cultivo mínimo - CM) e de rotação de culturas no peso de mil grãos (g). Passo Fundo, RS, 2000'.

\begin{tabular}{|c|c|c|c|c|}
\hline \multirow[t]{2}{*}{ Manejo de solo } & \multicolumn{3}{|c|}{ Sistemas de rotação de culturas } & \multirow[t]{2}{*}{ Média } \\
\hline & Monocultura $^{2}$ & $\begin{array}{l}\text { Um inverno sem } \\
\text { trigo }^{3}\end{array}$ & $\begin{array}{c}\text { Dois invernos sem } \\
\text { trigo }\end{array}$ & \\
\hline $\begin{array}{l}\text { PD } \\
\text { PCD } \\
\text { PCA } \\
\text { CM }\end{array}$ & $\begin{array}{l}31,70 \mathrm{aB} \\
27,97 \mathrm{bB} \\
31,07 \mathrm{aA} \\
32,63 \mathrm{aA}\end{array}$ & $\begin{array}{l}32,37 \mathrm{cB} \\
33,27 \mathrm{cA} \\
33,20 \mathrm{cA} \\
34,20 \mathrm{bA} \\
\end{array}$ & $\begin{array}{l}34,53 \mathrm{bA} \\
33,73 \mathrm{bcA} \\
33,13 \mathrm{dcA} \\
33,87 \mathrm{bcA}\end{array}$ & $\begin{array}{l}32,87 \mathrm{c} \\
31,66 \mathrm{~d} \\
32,47 \mathrm{~cd} \\
33,57 \mathrm{~b}\end{array}$ \\
\hline $\begin{array}{l}\text { PD } \\
\text { PCD } \\
\text { PCA } \\
\text { CM } \\
\end{array}$ & $\begin{array}{l}33,13 \mathrm{aB} \\
32,53 \mathrm{aB} \\
32,53 \mathrm{aB} \\
32,73 \mathrm{aB}\end{array}$ & $\begin{array}{l}36,67 \mathrm{aA} \\
36,20 \mathrm{aA} \\
35,47 \mathrm{abA} \\
35,60 \mathrm{abA} \\
\end{array}$ & $\begin{array}{l}35,73 \mathrm{aA} \\
34,27 \mathrm{bcA} \\
35,67 \mathrm{abA} \\
36,87 \mathrm{aA} \\
\end{array}$ & $\begin{array}{l}35,18 \mathrm{a} \\
34,33 \mathrm{ab} \\
34,56 \mathrm{a} \\
35,07 \mathrm{a}\end{array}$ \\
\hline Média & $31,79 \mathrm{~B}$ & $34,62 \mathrm{~A}$ & $34,72 \mathrm{~A}$ & \\
\hline $\begin{array}{l}\text { Médias seguidas pe } \\
\text { de Duncan. } \\
2 \text { Monocultura trigo } \\
3 \text { Trigo/soja e ervilh } \\
4 \text { Trigo/soja, aveia-b }\end{array}$ & núscula na coluna & na linha, não apresent & renças significativas a 5 & abilidade, \\
\hline
\end{tabular}




\section{CONCLUSÕES}

1. O preparo convencional de solo com arado de discos e o cultivo mínimo reduzem o número de queda.

2. O sistema de rotação de culturas com dois invernos sem trigo eleva o peso do hectolitro.

3. A monocultura de trigo eleva a força geral de glúten e os valores obtidos no teste de microssedimentação com lauril sulfato de sódio.

4. O peso de mil grãos é afetado pela interação de sistemas de manejo de solo, rotação de culturas e ano de cultivo.

\section{REFERÊNCIAS}

\section{AMERICAN ASSOCIATION OF CEREAL CHEMISTS} (Saint Paul, Estados Unidos). Approved methods of the American Association of Cereal Chemists. 8.ed. St. Paul, 1983. 2v.

AXFORD, D.W.E.; McDERMOTT, E.E.; REDMAN, D.G. Small-scale tests of bread-making quality. Milling Feed and Fertiliser, Uxbridge, v.161, p.1820, May 1978.

BALANÇAS DALLE MOLLE (Caxias do Sul, RS). Instruções para montagem da balança peso específico. Caxias do Sul, [19--].

BEQUETTE, R.K. Influence of variety and "environment" on wheat quality. Association of Operative Millers Bulletin, Leawood, p.5443-5450, May 1989.

BHATT, G.M.; PAULSEN, G.M.; KULP, K.; HEYNE, E. Preharvest sprouting in hard winter wheats: assessment of methods to detect genotypic and nitrogen effects and interactions. Cereal Chemistry, St. Paul, v.58, n.4, p.300-302, 1981.

BORGHI, B.; GIORDANI, G.; CORBELLINI, M.; VACCINO, P.; GUERMANDI, M.; TODERI, G. Influence of crop rotation, manure and fertilizers on bread making quality of wheat (Triticum aestivum L.). European Journal of Agronomy, Amsterdam, v.4, n.1, p.37-45, 1995.

BRASIL. Ministério da Agricultura, do Abastecimento e da Reforma Agrária. Instrução normativa n.1, de 27 de janeiro de 1999. Diário Oficial (da República Federativa do Brasil), Brasília, n.20, p.132-134, 29 jan. 1999. Seção 1.
BRASIL. Ministério da Agricultura e Reforma Agrária. Secretaria Nacional de Defesa Agropecuária. Regras para análise de sementes. Brasília, 1992. p.194195.

CAMPBELL, C.A.; DAVIDSON, H.R.; WARDER, F.G. Effects of fertilizer $\mathrm{N}$ and soil moisture on yield, yield components, protein content and $\mathrm{N}$ accumulation in the aboveground parts of spring wheat. Canadian Journal of Soil Science, Ottawa, v.57, p.311-327, 1977.

FINNEY, K.; YAMAZAKI, W. Quality of hard, soft and durum wheats. In: QUNSENBERRY, K.S.; REITZ, L.P. (Ed.). Wheat and wheat improvement. Madison : American Society of Agronomy, 1967. p.471-503. (ASA Agronomy, 13)

HIRANO, J. Effects of rain in ripening period on the grain quality of wheat. Japan Agricultural Research Quarterly, Ibaraki, v.10, n.4, p.168-173, 1976.

HUCKLESBY, D.P.; BROWN, C.M.; HOWELL, S.E.; HAGEMAN, R.H. Late spring applications of nitrogen for efficient utilization and enhanced production of grain and grain protein of wheat. Agronomy Journal, Madison, v.63, p.274-276, 1971.

INSTITUTO AGRONÔMICO DO PARANÁ (Londrina, PR). Recomendações técnicas para a cultura do trigo no Paraná: 1997. Londrina, 1997. 105p. (IAPAR. Circular, 92).

JIA, Y.; MASBOU, V.; AUSSENAC, T.; FABRE, J.; DEBAEKE, P. Effects of nitrogen fertilization and maturation conditions on protein aggregates and the breadmaking quality of Soissons, a common wheat cultivar. Cereal Chemistry, St. Paul, v.73, n.1, p.123-130, 1996.

LOPÉZ-BELLIDO, L.; FUENTES, M.; CASTILLO, J.E.; LÓPEZ-GARRIDO, F.J. Effects of tillage, crop rotation and nitrogen fertilization on wheat-grain quality grown under rainfed Mediterranean conditions. Field Crops Research, Amsterdam, v.57, n.3, p.265-276, 1998.

MANDARINO, J.M.G. Aspectos importantes para a qualidade do trigo. Londrina : Embrapa-CNPSo, 1993. p.12-24. (Embrapa-CNPSo. Documentos, 60).

NODA, K.; KAWABATA, C.; KAWAKAMI, N. Response of wheat grain to $\mathrm{ABA}$ and imbibition at low temperature. Plant Breeding, Berlin, v.113, p.53-57, 1994. 
PERTEN, H. Application of the falling number method for evaluating alpha-amylase activity. Cereal Chemistry, St. Paul, v.41, n.3, p.127-140, 1964.

PIMENTEL-GOMES, F. Experimentos em parcelas subdivididas: experimentos em faixa. In: Curso de Estatística Experimental. 5.ed. Piracicaba : USP, 1973. p.198-229.

RAO, A.C.S.; SMITH, J.L.; JANDHJYALA, V.K.; PAPENDICK, R.I.; PARR, J.F. Cultivar and climatic effects on the protein content of soft white winter wheat. Agronomy Journal, Madison, v.85, p.123$128,1993$.

SANTOS, H.P. dos; LHAMBY, J.C.B.; PRESTES, A.M.; REIS, E.M. Características agronômicas e controle de doenças radiculares de trigo, em rotação com ou- tras culturas de inverno. Pesquisa Agropecuária Brasileira, Brasília, v.33, n.3, p.277-288, mar.1998.

SANTOS, H.P. dos; REIS, E.M.; LHAMBY, J.C.B.; WOBETO, C. Efeito da rotação de culturas sobre o trigo, em sistema de plantio direto, em Guarapuava, PR. Pesquisa Agropecuária Brasileira, Brasília, v.31, n.4, p.259-267, abr. 1996.

SAS INSTITUTE (Cary, Estados Unidos). SAS system for elementary statistical analysis. Cary, 1987. $416 \mathrm{p}$.

ZENTNER, R.P.; BOWREN, K.E.; EDWARDS, W.; CAMPBELL, C.A. Effects of crop rotations and fertilization on yields and quality of spring wheat grown on a black Chernozem in north central Saskatchewan. Canadian Journal of Plant Science, Ottawa, v.70, p.383-397, 1990. 